\title{
Inhibition of Steel Corrosion in Simulated Oilfield Acidizing Medium Using Metallic Soap from Local Biomaterial
}

\author{
Ekemini Ituen ${ }^{1, *}$, James Asuquo ${ }^{1}$, Edidiong Essien ${ }^{2}$ \\ ${ }^{1}$ Materials and Oilfield Technology Research Group, Department of Chemistry, University of Uyo, Uyo, Nigeria \\ ${ }^{2}$ Department of Environmental Science, Cyprus International University, Mersin, Turkey
}

Email address:

ebituen@gmail.com (E. Ituen)

${ }^{*}$ Corresponding author

\section{To cite this article:}

Ekemini Ituen, James Asuquo, Edidiong Essien. Inhibition of Steel Corrosion in Simulated Oilfield Acidizing Medium Using Metallic Soap from Local Biomaterial. International Journal of Oil, Gas and Coal Engineering. Vol. 5, No. 6, 2017, pp. 158-166. doi: $10.11648 /$ j.ogce.20170506.16

Received: February 12, 2017; Accepted: March 9, 2017; Published: November 29, 2017

\begin{abstract}
Metallic soap prepared by saponification of melon seed oil (Cucumeropsis mannii N) with copper (II) salt was investigated as corrosion inhibitor for mild steel corrosion in $1 \mathrm{M}$ hydrochloric acid solution. Results reveal that the metallic soap inhibited the corrosion process by spontaneous physical adsorption of the phytochemicals of the seed oil onto the mild steel surface. The highest inhibition efficiency of $82.7 \%$ was obtained at $30^{\circ} \mathrm{C}$ with $10 \mathrm{~g} / \mathrm{L}$ of the metallic soap, but this efficiency decreased with increase in temperature. The fractional surface coverage data best fitted into Temkin adsorption model which was used to predict the inhibitor-metal binding strength as a function of temperature. Atomic Absorption Spectrophotometric assessment of copper (II) ion composition in the inhibitor afforded a value within the safe limit for health, environment and personnel. Density functional theorem (DFT) studies provided supportive evidence of possible involvement of the fatty acid phyto-components in the adsorption process. The mechanism of inhibition was also predicted by applying the recent temperature coefficient of inhibition efficiency equation.
\end{abstract}

Keywords: Adsorption, Bio-Metallic Soap, Melon Seed Oil, Metallic Soap

\section{Introduction}

Corrosion is a major problem in the oilfield. It may be brought about by chemical or electrochemical action of dissolved acidic gases in the reservoirs, acid $(\mathrm{HCl})$ from well acidizing and fracturing fluids, actions of sulphate reducing bacteria (SRB), among others. Corrosion scientists and engineers are in unending search for substances (inhibitors) that can effectively reduce the rate of corrosion because it is difficult to stop corrosion. Several substances such as plant extracts [1-3], synthetic organic compounds [4, 5], polymers [6], dyes [7] and organo-metallic compounds [8] have been reported to inhibit corrosion. Some of these materials/substances are not environmentally friendly; others are very expensive or non-renewable. In search for effective and inexpensive and ecofriendly corrosion inhibitors from renewable source, we have considered the use of metallic soap obtained from green sources.
Metallic soaps are simple to prepare and the availability of electron-rich sites on their fatty acid functionalities motivated us to investigate them as the corrosion inhibitors. We have reported the anticorrosive effectiveness of metallic soap obtained as saponification product of Zinc (II) ions and melon seed oil [9]. In the present study, the metal ion was replaced with Copper (II) ions to obtain a light-blue bio-metallic soap (Cu-soap). The choice of melon seed oil was motivated by its broad fatty acids such as stearic, palmitic, oleic and linoleic acids [10]. These fatty acids and melon seed oil have been reported to possess bioactivity against micro-organisms such as bacteria, including sulphates reducing bacteria (SBR) which also cause oilfield corrosion $[11,12]$. This study also seeks to find alternative applications for metallic soaps than being used as one of the components of paints $[13,14]$. 


\section{Experimental Procedure}

\subsection{Materials and Sample Surface Preparation}

Mild steel sheets (of composition C (0.065), Si (0.24), Mn (1.58), P (0.011), S (0.003), Cu (0.01), Cr (0.022), Nb (0.057), $\mathrm{V}$ (0.005), Ti (0.024), B (0.0006), Fe (balance)) were purchased from construction materials market in Uyo, the capital city of Akwa Ibom State in Nigeria. They were mechanically press-cut into coupons of $4 \mathrm{~cm} \times 4 \mathrm{~cm}$ in size and used to simulate oilfield steel materials in the study without polishing. They were however degreased in absolute ethanol, rinsed in distilled water, dried in air after rinsing in acetone and stored in a desiccator before use. The corroding medium was simulated by preparing $1.0 \mathrm{M}$ analytical grade $\mathrm{HCl}$ using double distilled water. The inhibitor was synthesized and characterized as earlier reported [10] and was prepared into different concentrations ( $2 \mathrm{mg} / \mathrm{L}$ to $10 \mathrm{mg} / \mathrm{L}$ ).

\subsection{Weight Loss Technique}

Pre-weighed mild steel coupons were totally immersed the test solutions for 10 hours, retrieved, cleaned using ASTM G1 standard [15], rinsed in distilled water, dried in acetone, and re-weighed using a FA2104, a digital weighing balance with sensitivity $\pm 0.0001 \mathrm{~g}$. The weight loss study was carried out using standard procedures earlier reported [9]. The corrosion rate and inhibition efficiency were determined using the mass loss relationship below (Equation 1-2):

$$
\begin{gathered}
\beta=\frac{m_{1}-m_{2}}{A t} \\
\% I=100\left(\frac{\beta_{b}-\beta_{i}}{\beta_{b}}\right)
\end{gathered}
$$

where $\beta\left(\mathrm{mgcm}^{-2} \mathrm{~h}^{-1}\right)$ is the corrosion rate, $m_{1}$ and $m_{2}(\mathrm{mg})$ are the weights before and after immersion respectively in the test solutions, $\left(\mathrm{cm}^{2}\right)$ is the surface area of the coupons, $t(\mathrm{~h})$ is the total immersion time, $\beta_{1}$ and $\beta_{2}$ are the corrosion rates in the absence and presence of the inhibitor respectively.

\subsection{Gasometric Method}

Gasometric assembly was used to measure the volume of hydrogen evolved during the corrosion progress at fixed time intervals. When acid reacts with metal, hydrogen is liberated, and the volume was measured as earlier reported [16]. The test solutions were studied at $303 \mathrm{~K}$ to $333 \mathrm{~K}$ maintained in water bath. Hydrogen evolution rates $(R V)$ for both the free acid $\left(R V_{b}\right)$ and the inhibited solutions $\left(R V_{i}\right)$ were correlated to the mild steel corrosion rate (Equation 3), where and are the volumes of hydrogen evolved at time and respectively. Inhibition efficiency was computed from Equation 4 [17]:

$$
\begin{gathered}
R V=\left(\left(V_{1}-V_{0}\right) /\left(t_{1}-t_{0}\right)\right) \\
\% I_{H}=100\left(\frac{R V_{b}-R V_{i}}{R V_{b}}\right)
\end{gathered}
$$

\subsection{Determination of $\mathrm{Cu}^{2+}$ Ions}

Copper (II) ions content was determined by Atomic Absorption Spectrometry using model 939/959 UNICAM Spectrophotometer. De-ionized water was used as blank in standardizing the instrument. Calibration curve was constructed by plotting absorbance versus concentration. By interpolation, the concentration of the metal in sample was determined [18].

\subsection{Theoretical Study}

Density Functional Theory (DFT) at the B3LYP/6-31G* basis set level using Spartan '10 wave function package was used for quantum chemical calculations. Full geometry optimization of the structures for the major fatty acids in metallic soap as neutral molecules was carried out. Other parameters were calculated theoretically and used to describe the inhibitor-metal interactions.

\section{Results and Discussion}

\subsection{Corrosion Rate}

Corrosion rates of the mild steel coupons in $1.0 \mathrm{M} \mathrm{HCl}$ were calculated in both the uninhibited and inhibited solutions (Table 1). Corrosion rate increases with increase in temperature. Compared to the inhibited solution, corrosion rate was higher in the free acid solution, which implies that the bio-metallic soap actually retarded the mild steel corrosion. The effectiveness of the $\mathrm{Cu}$-soap is concentration dependent and increases with inhibitor loading. Corrosion rate on the other hand decreases as concentration of the $\mathrm{Cu}$ -

\begin{tabular}{|c|c|c|c|c|c|c|c|c|}
\hline \multicolumn{9}{|c|}{ Corrosion rates $\left(\mathrm{mgcm}^{-2} \mathrm{~h}^{-1}\right)$} \\
\hline \multirow[t]{2}{*}{$C(g / L)$} & \multicolumn{3}{|c|}{ Weight loss measurement } & \multicolumn{5}{|c|}{ Hydrogen evolution measurement } \\
\hline & $303 \mathrm{~K}$ & $313 \mathrm{~K}$ & $323 \mathrm{~K}$ & $333 \mathrm{~K}$ & $303 \mathrm{~K}$ & $313 \mathrm{~K}$ & $323 \mathrm{~K}$ & $333 \mathrm{~K}$ \\
\hline 0 & 1.781 & 4.87 & 15.47 & 23.51 & 1.781 & 4.87 & 15.47 & 23.51 \\
\hline 2 & 0.58 & 1.85 & 6.58 & 11.22 & 0.61 & 0.59 & 0.54 & 0.49 \\
\hline 4 & 0.5 & 1.55 & 5.97 & 10.35 & 0.67 & 0.63 & 0.58 & 0.55 \\
\hline 6 & 0.42 & 1.39 & 5.23 & 9.50 & 0.69 & 0.65 & 0.6 & 0.57 \\
\hline 8 & 0.37 & 1.20 & 4.73 & 8.30 & 0.72 & 0.69 & 0.65 & 0.61 \\
\hline 10 & 0.31 & 1.06 & 4.10 & 7.40 & 0.76 & 0.72 & 0.70 & 0.66 \\
\hline
\end{tabular}
soap increases. Similar trends have been reported in literature [19-21].

Table 1. Corrosion rates for different concentrations of cu-soap at different temperatures.

$\mathrm{Cu}$-soap is a more efficient inhibitor than $\mathrm{Zn}$-soap which was earlier reported [14] despite that $\mathrm{HCl}$ is more corrosive than
$\mathrm{H}_{2} \mathrm{SO}_{4}$. This may be attributed to difference in electronic structure of $\mathrm{Cu}$ and $\mathrm{Zn}$. Copper has a vacant orbital for 
electronic interactions with phytochemicals melon seed oil. With this, $\mathrm{Cu}$ forms a divalent ion which interacts more strongly with $\mathrm{Fe}$ in steel by electrostatic or Columbic forces than zinc. Copper soap would likely form a stronger adsorbed/protective film on the mild steel surface than zinc soap.

\subsection{Inhibition Efficiency}

Inhibition efficiency $(\% I)$ increases with increase in inhibitor concentration and decreases with increase in temperature (Table 2). Maximum inhibition efficiency of
$82.7 \%$ and $76.3 \%$ were obtained from weight loss and hydrogen evolution measurements respectively at $303 \mathrm{~K}$. This efficiency maybe attributed to electrostatic interactions between its charged sites of the organic phytochemicals such as palmitic acid (10.57\%), stearic acid (8.33\%), oleic acid (13.65\%), linoleic (62.14\%) and linolenic $(5.29 \%)$ acids $[1,10]$. However, spectroscopic analysis of the corrosion products could offer more data for explaining this.

Table 2. Inhibition efficiency for different concentrations of cu-soap at different temperatures.

\begin{tabular}{|c|c|c|c|c|c|c|c|c|}
\hline \multirow[t]{2}{*}{$\mathrm{C}(\mathrm{g} / \mathrm{L})$} & \multicolumn{4}{|c|}{ Weight loss measurement } & \multicolumn{4}{|c|}{ Hydrogen evolution measurement } \\
\hline & $303 \mathrm{~K}$ & $313 \mathrm{~K}$ & $323 \mathrm{~K}$ & $333 \mathrm{~K}$ & $303 \mathrm{~K}$ & $313 \mathrm{~K}$ & $323 \mathrm{~K}$ & $333 \mathrm{~K}$ \\
\hline 2 & 67.3 & 62.1 & 57.5 & 52.3 & 61.2 & 59.3 & 54.1 & 50.2 \\
\hline 4 & 72.1 & 68.2 & 61.4 & 56.0 & 66.7 & 62.5 & 58.1 & 55.4 \\
\hline 6 & 76.1 & 71.4 & 66.2 & 59.6 & 69.4 & 65.3 & 60.3 & 57.2 \\
\hline 8 & 79.4 & 75.3 & 69.4 & 64.7 & 72.1 & 68.8 & 65.1 & 61.3 \\
\hline 10 & 82.7 & 78.3 & 73.5 & 67.1 & 76.3 & 72.0 & 69.5 & 66.2 \\
\hline
\end{tabular}

\subsection{Temperature Coefficient of Inhibition Efficiency}

A new approach relating the degree of responsiveness of inhibition efficiency to changes in temperature has been reported [12] to be useful in predicting the mechanism of corrosion inhibition. According to the model derived by one of our authors, a linear relationship is assumed to exist between temperature change and the change in inhibition efficiency for a given inhibitor in an aggressive medium. Suppose the inhibition efficiency at an initial temperature, is, and the Inhibition efficiency at a new temperature is, then the fractional change in inhibition efficiency per initial inhibition efficiency per Kelvin rise in temperature defines the temperature coefficient of corrosion inhibition efficiency, $\mu$, such that

$$
\frac{I_{t}-I_{0}}{I_{0} \Delta T}=\mu
$$

Rearranging equation 5 gives equation 6

$$
I_{T}=I_{0} \mu \Delta T+I_{0}
$$

A plot of $I_{T}$ against $\Delta T$, therefore should yield straight lines with slope equal to $I_{0} \mu$ and intercept equal to $\mu$ as shown in figure 1 . The calculated values of $\mu$ (Table 3 ) for the inhibition of mild steel corrosion by different concentration of copper soap in the sulphuric acid solution afforded negative values of $\mu$ which indicate decrease in inhibition efficiency with increase in temperature. According to this model, this observation is associated with physical adsorption mechanism [22].

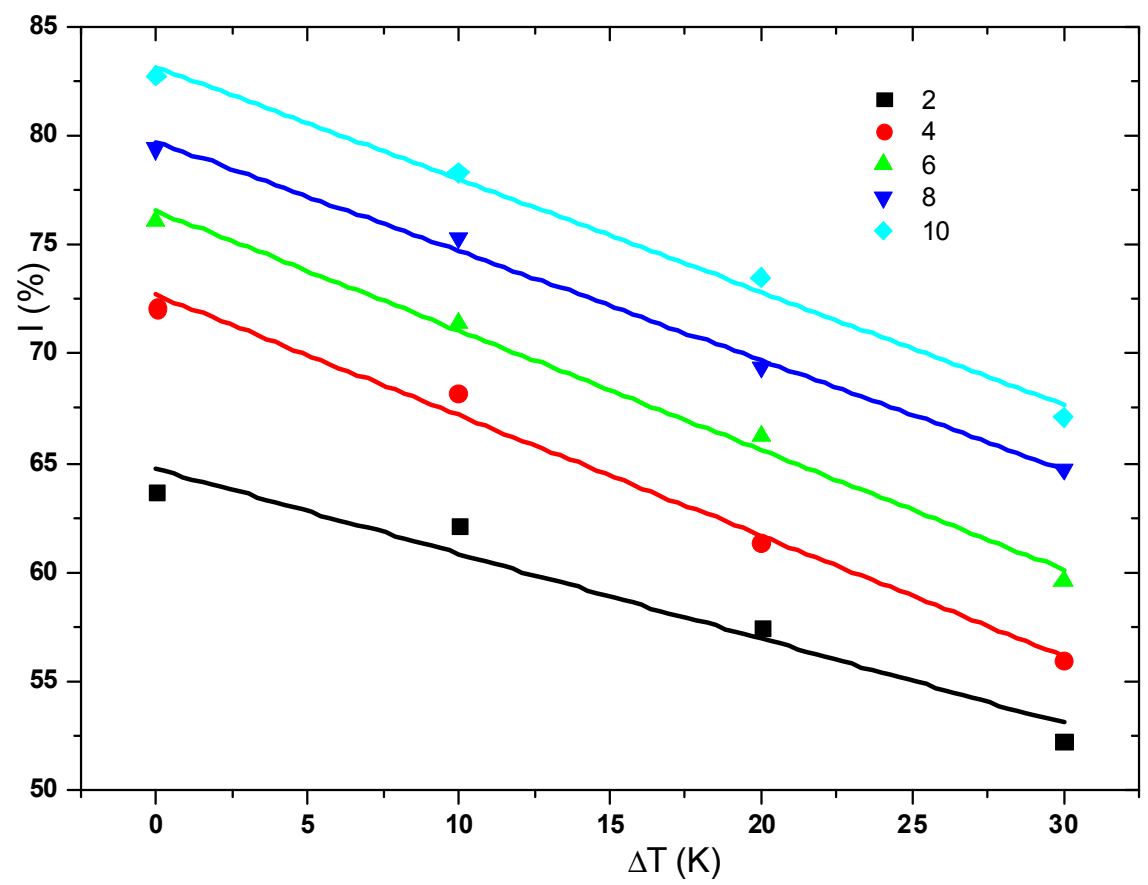

Figure 1. Temperature coefficient of inhibition efficiency plot. 
Table 3. Temperature coefficient of inhibition efficiency using weight loss data.

\begin{tabular}{llllll}
\hline $\mathbf{C}(\mathbf{g} / \mathbf{L})$ & $\mathbf{2}$ & $\mathbf{4}$ & $\mathbf{6}$ & $\mathbf{8}$ & $\mathbf{1 0}$ \\
\hline$-\mu$ & 0.0687 & 0.0705 & 0.0667 & 0.0590 & 0.0584 \\
\hline
\end{tabular}

\subsection{Effect of Temperature and Kinetic Studies}

As earlier observed, corrosion rate increases with increase in temperature. In order to further describe the effect of temperature on the corrosion inhibition process, the corrosion rate data were fitted into Arrhenius kinetic model (figure 2) according to Equation 7 and the deduced activation parameters are shown in Table 4. The activation energy obtained was higher in the inhibited solution than the free acid solution. From first principle, activation energy is the energy barrier that molecules of the free acid must possess in other to attack and corrode the mild steel surface or dissolve it. This barrier was found to be higher in the presence of the inhibitor which implies that introduction of the $\mathrm{Cu}$-soap deepens the location of the iron ions in the metal lattice, requiring more energy to cross over and become metal cations [23]. This explains the high inhibition efficiency and hence protection of the metal.

$$
\log \beta=\log A-\frac{E_{a}}{2.303 R T}
$$

where $\beta$ is the corrosion rate, $E_{a}$ is the activation energy, $A$ is the pre-exponential or frequency factor, $R$ is the universal gas constant and $T$ is the absolute temperature.

Typically, the pre-exponential factor expresses the fraction of the acid molecules that possess enough energy to attack the mild steel surface and dissolve it, as governed by the Maxwell-Boltzmann law. Theoretically, this fraction can run between zero and unity (i.e. $0 \leq A \leq 1$ ), depending on the magnitude of activation energy and temperature. Our results are in agreement with these theoretical limits, showing adherence of $\mathrm{Cu}$-soap adsorption on mild steel to Arrhenius kinetic model. The free acid solution has the highest value of ' $A$ ' (Table 4) indicating that the free acid has the highest fraction of molecules with enough energy to attack the mild steel surface. Decrease in value of ' $A$ ' as concentration of $\mathrm{Cu}$-soap increases implies that the corrosion inhibitor is more effective when concentration is increased.

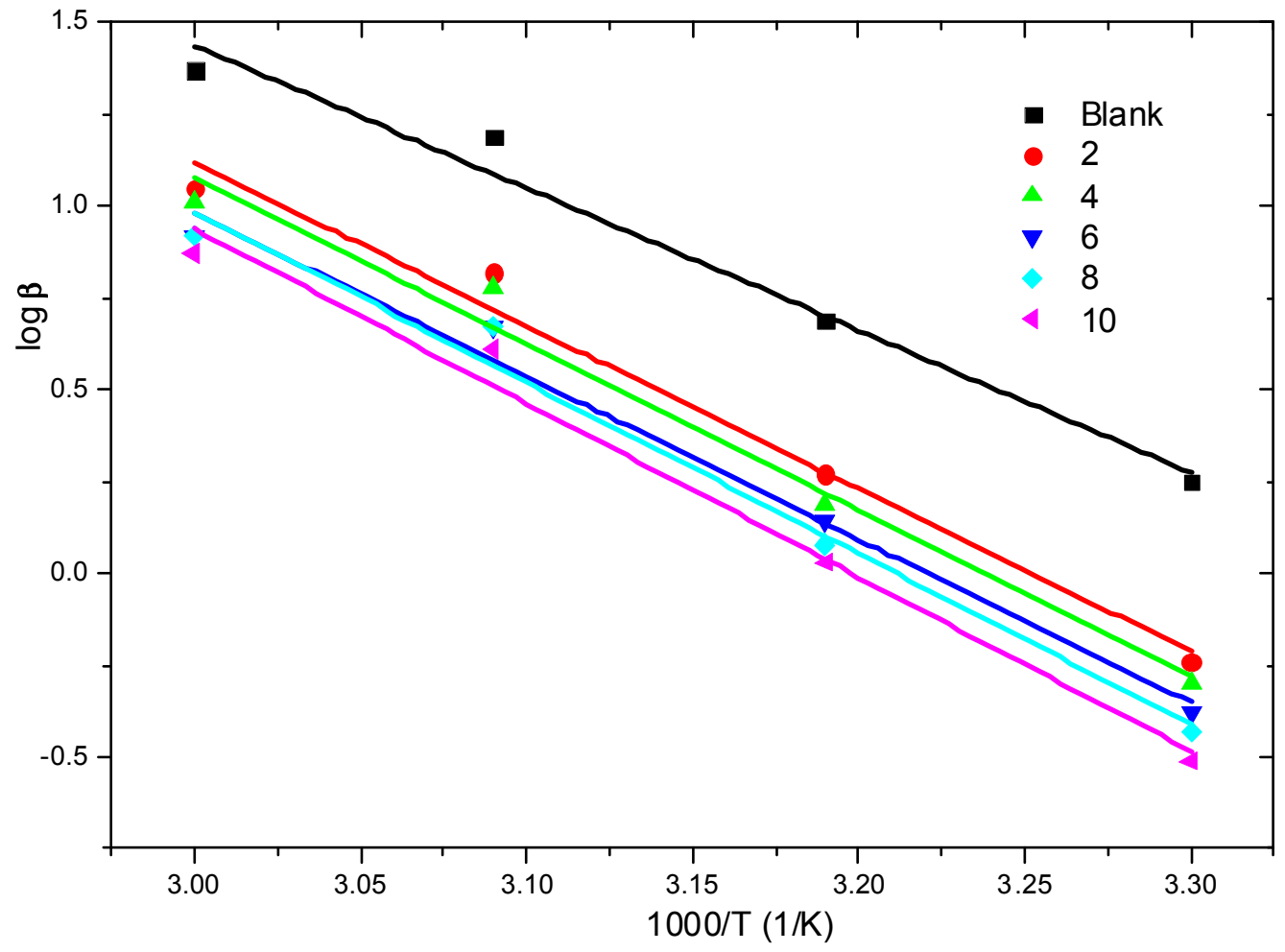

Figure 2. Fitting of corrosion rate into arrhenius kinetic model.

Table 4. Activation parameters from Arrhenius kinetic model.

\begin{tabular}{lllll}
\hline \multicolumn{3}{c}{ Weight loss } & \multicolumn{2}{l}{ Hydrogen evolution } \\
\hline $\mathbf{C}(\mathbf{g} / \mathbf{L})$ & $\mathbf{A}$ & $\boldsymbol{E}_{\boldsymbol{a}}(\mathbf{k J} / \mathbf{m o l})$ & $\mathbf{A}$ & $\boldsymbol{E}_{\boldsymbol{a}}(\mathbf{k J} / \mathbf{m o l})$ \\
\hline 0 & 0.813 & 7.391 & 0.813 & 7.394 \\
2 & 0.233 & 8.501 & 0.284 & 8.118 \\
4 & 0.192 & 8.693 & 0.223 & 8.348 \\
6 & 0.162 & 0.846 & 0.248 & 8.214 \\
8 & 0.140 & 8.903 & 0.203 & 8.291 \\
10 & 0.114 & 9.150 & 0.175 & 8.348 \\
\hline
\end{tabular}

\subsection{Adsorption Considerations}

The mechanism of adsorption may be predicted from the trend of inhibition efficiency and activation energy. From our results, there was a decrease in inhibition efficiency with increase in temperature, and the activation energy of the uninhibited test solution was greater than that of the inhibited solution $\left(E_{a}\right.$ (uninhibited) $>E_{a}$ (inhibited)). This trend has 
been associated with physical adsorption mechanism [19]. In comparison, the mechanism of adsorption of $\mathrm{Cu}$ - and $\mathrm{Zn}$ soap of melon seed oil on mild steel surface is similar. An increase in solution temperature decreases the number of adsorbed inhibitor molecules, resulting in desorption and a decrease in inhibition efficiency. The $\mathrm{Cu}$-soap may affect the inhibition efficiency in two possible mechanisms: either by decreasing metal surface available for acid attack (geometric blocking effect) or by modifying (increasing) the activation energy of the anodic or cathodic reactions occurring in the inhibitor-free surface [24]. The higher activation energies imply increased energy barrier, slow reaction and sensitivity of reaction rate to temperature variations.

The mechanism of adsorption of corrosion inhibitors are best described using adsorption isotherms [25]. The fractional surface coverage data were fitted into familiar adsorption isotherms like Langmuir, Temkin, Freundlich, Florry-Huggins, and El-Awady et al [21]. Regression coefficients of the lines obtained was highest with Temkin adsorption isotherm implying that the parameters and assumptions used to derive this model can be used to approximate the nature of the adsorption of our $\mathrm{Cu}$-soap. This model assumes that the adsorption of charged molecules on a charged heterogeneous surface is given by the relationship:

$$
e^{-2 a \theta}=K C
$$

Where " $a$ " is the molecular interaction parameter, is the degree of surface coverage; is the equilibrium constant of adsorption and $C$ is the concentration of inhibitor. A relationship had been established between and free energy of adsorption, as shown in Equation 9.

$$
\Delta G_{a d s}^{*}=-R T \ln (55.5 K)
$$

where 55.5 represents the concentration of water and $T$ is the absolute temperature. Linearized plot of surface coverage $(\theta)$ against the logarithm of $\mathrm{Cu}$-soap concentrations at different temperatures according to the Temkin model (Fig. 3) afforded some adsorption parameters (Table 5). The values of " $a$ " in all cases are negative implying that repulsion exists in the adsorbed layer [17]. The equilibrium constant of adsorption, $K$, can be used to describe the strength of binding between the metal and inhibitor. The obtained value of $K$ decreases with increase in temperature which implies that the binding strength weakens with increase in temperature possibility of desorption of inhibitor molecules. This trend coupled with values of $\Delta G_{a d s}$ less negative than $-40 \mathrm{kJmol}^{-1}$ obtained has been associated with spontaneous physical adsorption mechanism [22].

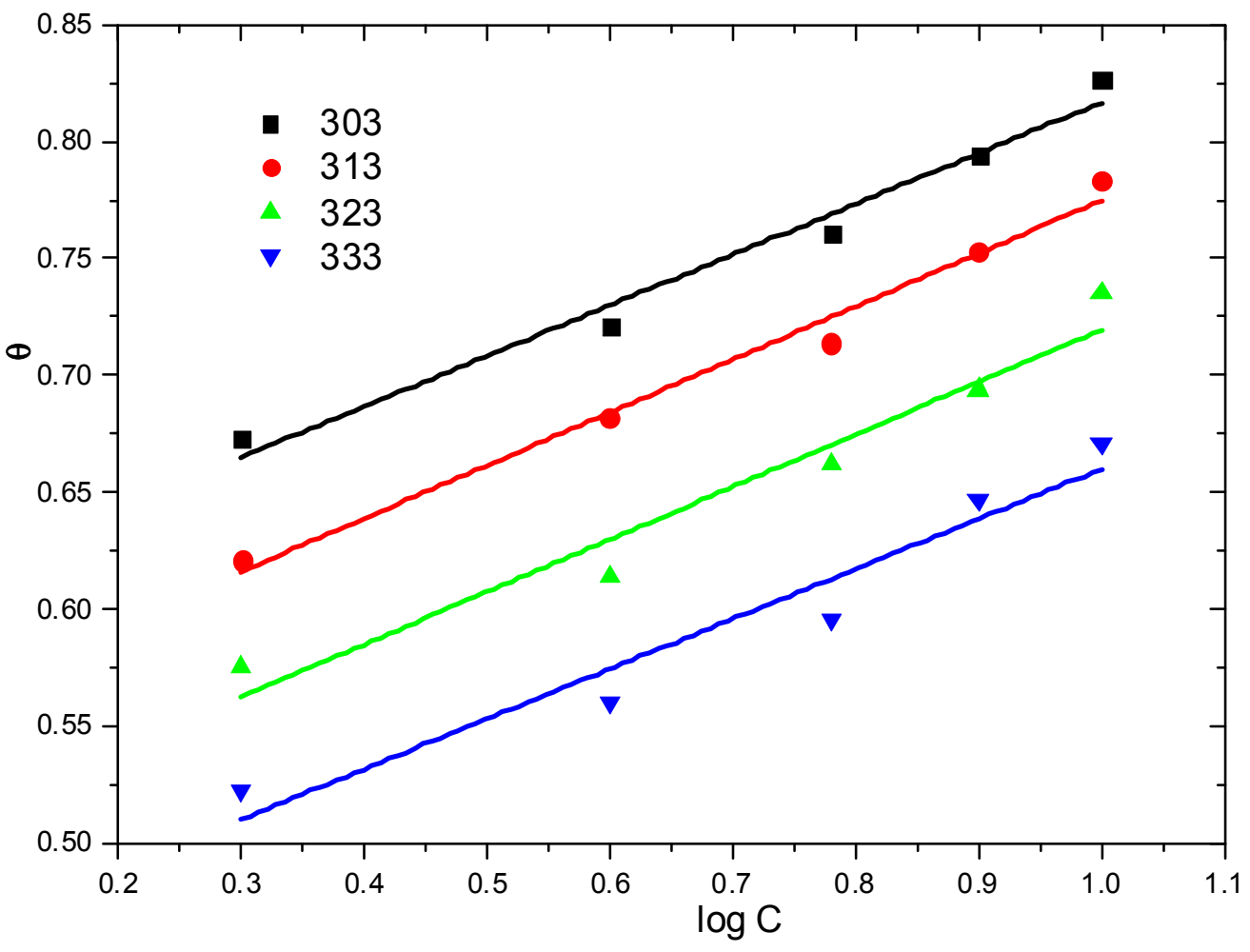

Figure 3. Temkin adsorption isotherm.

Table 5. Adsorption parameters calculated from temkin adsorption isotherm.

\begin{tabular}{llll}
\hline $\mathbf{T}(\mathbf{K})$ & $\mathbf{A}$ & $\boldsymbol{K}\left(\mathbf{x 1 0} \mathbf{0}^{-3}\right)$ & $\Delta \boldsymbol{G}_{\text {ads }}^{*}\left(\mathbf{k J m o l}^{-\mathbf{1}}\right)$ \\
\hline 303 & -26.32 & 4.37 & -3.569 \\
313 & -25.64 & 3.91 & -3.976 \\
323 & -25.50 & 3.44 & -4.447 \\
333 & -24.32 & 3.05 & -4.917 \\
\hline
\end{tabular}

\subsection{Thermodynamic Studies}

$$
\begin{gathered}
\beta=\frac{R T}{N h} \exp \left(\frac{\Delta S^{*}}{R}\right) \exp \left(\frac{\Delta H^{*}}{R T}\right) \\
\Delta G_{a d s}^{*}=\Delta H^{*}-T \Delta S^{*}
\end{gathered}
$$

where $N$ is the Avogadro's number, $\Delta S^{*}$ is the standard 
entropy change, $\Delta H^{*}$ is the standard enthalpy change, $\Delta G_{a d s}^{*}$ is the free energy change of adsorption and $h$ is the planks constant. The slope and intercept of a plot of $\log C R /$ $T$ against $1 / T$ (Fig. 4) afforded values of standard enthalpy and entropy changes respectively.

Like $E_{a}$, the $\Delta H^{*}$ increases with increase in concentration of the inhibitor (Table 6 ) the positive Like, the increases with increase in concentration of the inhibitor (Table 6) the positive values imply the endothermic nature of the adsorption process. The negative entropy increases gradually with the presence of the inhibitor compared to that of the uninhibited solution, possibly indicating the spontaneous nature of the adsorption process [26, 27]. Values of obtained by application of Equation 11 were less negative than -40 $\mathrm{kJmol}^{-1}$ which further supports spontaneous physical adsorption mechanism earlier proposed.

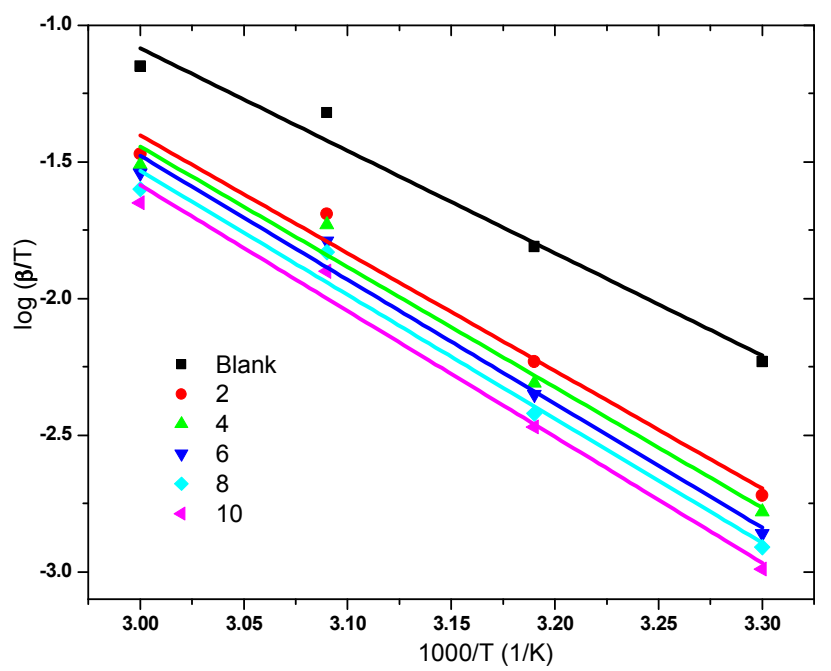

Figure 4. Fitting of corrosion rate into transition State model.

Table 6. Thermodynamic parameters.

\begin{tabular}{lllllll}
\hline \multirow{2}{*}{$\mathbf{C}(\mathbf{g} / \mathbf{L})$} & $\begin{array}{l}\Delta \boldsymbol{H}^{*} \\
\left.\mathbf{( J m o l}^{-\mathbf{1}}\right)\end{array}$ & $\begin{array}{c}\Delta \boldsymbol{S}^{*} \\
\left(\mathbf{k J m o l}^{-\mathbf{1}}\right)\end{array}$ & $\mathbf{3 0 3 ~ \mathbf { ~ }}$ & $\mathbf{3 1 3 ~ \mathbf { ~ }}$ & $\mathbf{3 2 3 ~ K}$ & $\mathbf{3 3 3 ~ K}$ \\
\hline 0 & 7.122 & 40.33 & 12.21 & 12.62 & 13.02 & 13.42 \\
2 & 8.176 & 42.56 & 12.89 & 13.31 & 13.74 & 14.16 \\
4 & 8.245 & 45.87 & 13.89 & 14.35 & 14.80 & 15.27 \\
6 & 8.233 & 51.53 & 15.61 & 16.12 & 16.63 & 17.15 \\
8 & 8.655 & 50.65 & 15.34 & 15.84 & 16.35 & 16.86 \\
10 & 8.903 & 53.10 & 16.08 & 16.61 & 17.14 & 17.67 \\
\hline
\end{tabular}

\subsection{Theoretical Studies}

Some structures of the phytochemicals in the melon seed oil were theoretically simulated so as to gain insight into their adsorption/interaction behaviour using density functional theory (DFT) at the B3LYP/6-31G* basis set computed from Spartan '10 wavefunction software. The full optimized geometries, frontier molecular orbitals (HOMO and LUMO), electron density distributions (figure 5) as well as orbital energies, band gap energy, dipole moments and global hardness and softness (Table 7), which are parameters that influence electronic interactions with the metal surface were obtained. Excellent corrosion inhibitors are usually those compounds who not only offer electrons to unoccupied orbital of the metal, but also accept free electrons from the metal.

The energy of the LUMO indicates the ability of the molecule to accept electrons; hence these are the acceptor sites. The lower the value of $\mathrm{E}_{\mathrm{LUMO}}$, the more probable it is that the molecule would accept electrons. Good inhibitors also have high HOMO energies, which indicate their tendencies to donate electrons to vacant metal orbitals and form a bond. The dipole moments obtained shows that apart from linoleic acid, other phytochemicals are of close polarity range. Due to their densities, they will get adsorbed onto the metal surface by way of their polar functional groups, while the non-polar hydrocarbon moiety form flattened protective films on the metal surface, hence corrosion inhibition.

Table 7. Theoretically calculated parameters using DFT at the B3LYP/6$31 G^{*}$ basis set.

\begin{tabular}{lllllll}
\hline Fatty acid & $\begin{array}{l}\mathbf{E}_{\text {Hомо }} \\
(\mathbf{e V})\end{array}$ & $\begin{array}{l}\mathbf{E}_{\text {LUмo }} \\
(\mathbf{e V})\end{array}$ & $\begin{array}{l}\boldsymbol{\Delta} \mathbf{E} \\
(\mathbf{e V})\end{array}$ & $\begin{array}{l}\boldsymbol{\mu} \\
(\mathbf{d e b y e})\end{array}$ & $\mathbf{A}$ & $\mathbf{B}$ \\
\hline Stearic & -7.47 & 0.29 & 7.76 & 1.26 & 3.38 & 0.2577 \\
Palmitic & -7.46 & 0.30 & 7.76 & 1.28 & 3.38 & 0.2577 \\
Oleic & -6.43 & 0.24 & 6.67 & 1.40 & 3.34 & 0.2999 \\
Linoleic & -6.30 & 0.33 & 6.63 & 1.78 & 3.32 & 0.3017 \\
Linolenic & -6.31 & $\mathrm{~s} 0.33$ & 6.64 & 1.32 & 3.32 & 0.3012 \\
\hline
\end{tabular}

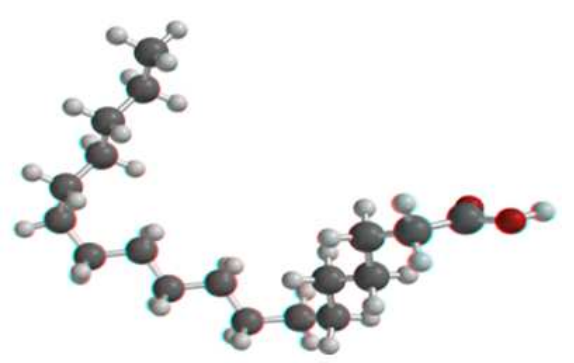

Optimized stearic acid structure

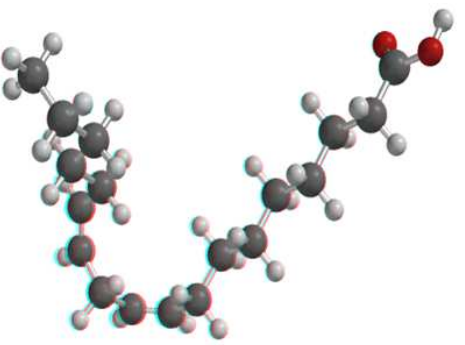

Optimized linoleic acid structure

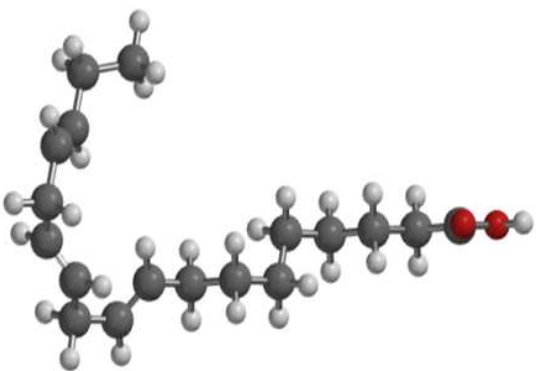

Optimized linolenic acid structure 


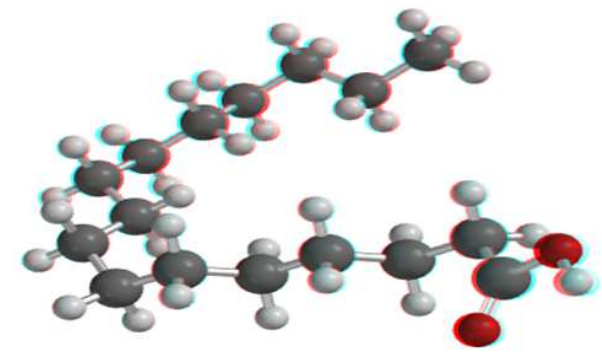

Optimized palmitic acid structure

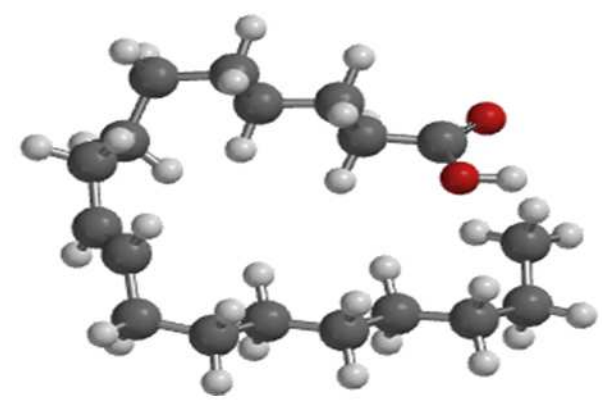

Optimized oleic acid structure

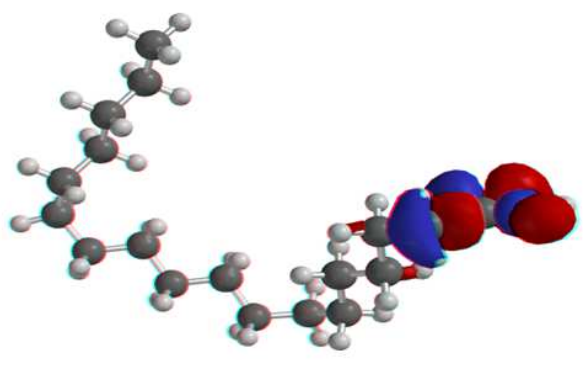

HOMO density of stearic acid

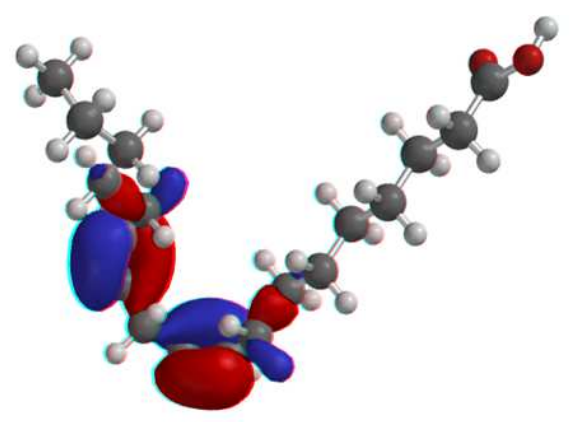

HOMO density of linoleic acid

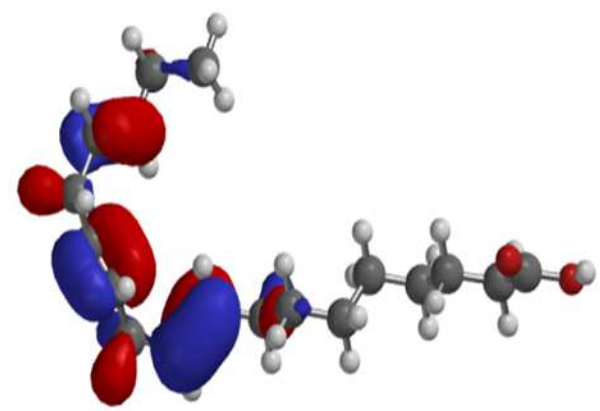

HOMO density of linolenic acid

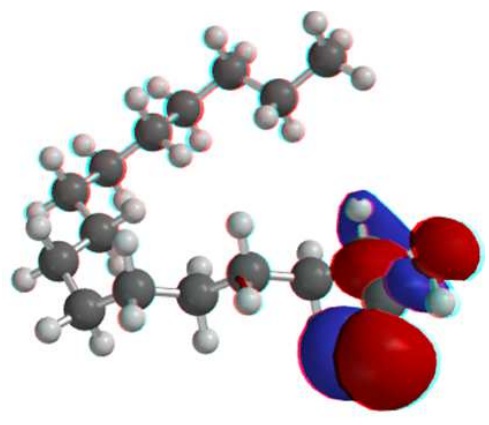

HOMO density of palmitic acid

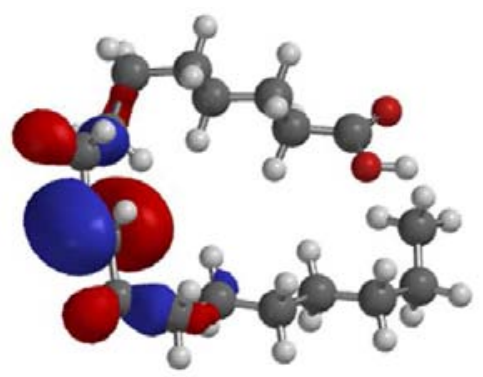

HOMO density of oleic acid

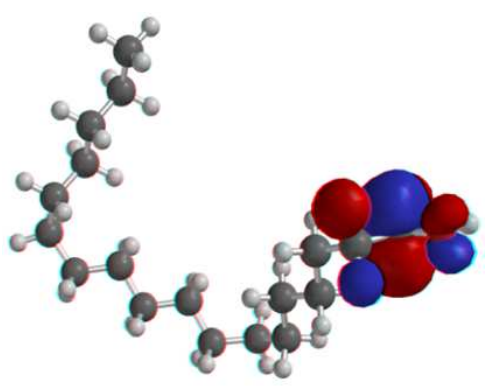

LUMO density of stearic acid

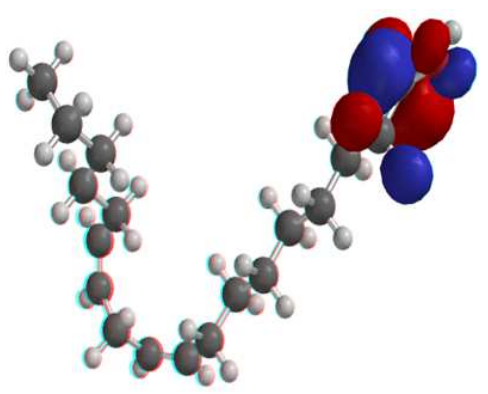

LUMO density of linoleic acid

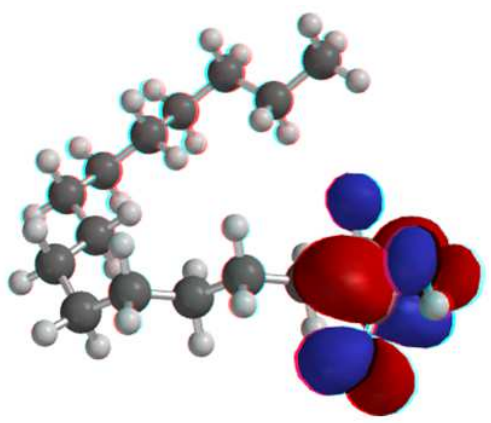

LUMO density of palmitic acid 


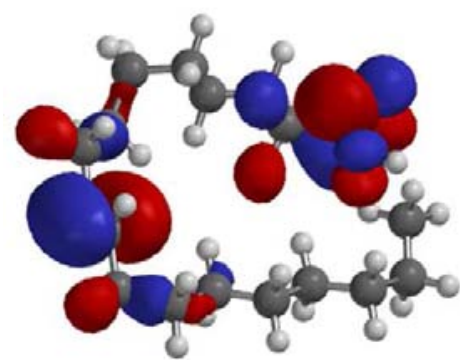

LUMO density of oleic acid

Figure 5. Molecular simulations for the phytochemicals using DFT at the B3LYP/6-31G* basis set.

\subsection{Health, Safety and Environmental Considerations}

Since heavy metals are known to be toxic, therefore, the amount of copper (II) ions present in the inhibitor was evaluated to assess its friendliness or otherwise. The amount of copper obtained from AAS measurement was $1.28 \pm 0.11$ $\mu \mathrm{g}$ per $1 \mathrm{~g}$ of inhibitor. This value falls within the Recommended Dietary Allowance and Tolerable Upper Intake Level provided by both EPA and WHO. Based on this result, our copper metallic soap would be ecologically friendly and non-toxic. Copper does not break down in the environment. Its accumulation in water may have slight effects on biodiversity in case of exposure.

In addition, ancient civilization exploited the antimicrobial properties of copper long before microbes were well understood. Some microorganisms like SRB initiate corrosion. Since bacteria are rapidly killed on by copper [28, 29] (what is called contact killing), the antibacterial property of copper could also be of advantage if our metallic soap is applied in oilfield. However, there is need for further studies on this.

\section{Conclusion}

Metallic soap prepared by saponification of melon seed oil (Cucumeropsis mannii $N$ ) with copper (II) salt was investigated as green inhibitor for mild steel corrosion in sulphuric acid solution at various temperatures. The metallic soap offered good inhibitive effectiveness at the temperatures studied but became less effective as temperature increased. Adsorption of $\mathrm{Cu}$-soap molecules on steel surface is spontaneous and involves physical adsorption mechanism. Temkin adsorption model best describes $\mathrm{Cu}$-soap adsorption and reveals slight weakening of the inhibitor-metal binding strength with increase in temperature. Thermodynamic treatment of data also reveals endothermic adsorption process. $\mathrm{Cu}$-soap would make a non-toxic corrosion inhibitor and replacement for toxic chemical inhibitors used as additives in drilling and well treatment fluids.

\section{References}

[1] Ashassi-Sorkhabi, H. and Seifzadeh, D. (2006). The inhibition of steel corrosion in hydrochloric acid solution by juice of Prunus cerasus. International J. Electrochem. Sci, 1 (1), 92-6.
[2] Ajayi, O. O., Omotosho, O. A., Ajanaku, K. O. and Olawore, B. O. (2011). Degradation study of Aluminium alloy in $2 \mathrm{M}$ hydrochloric acid in the presence of Chromolaena odorata. $J$. Eng. Appl. Sci, 6 (1), 10-17.

[3] Davis, G. D. and Von Fraunhofer, J. (2003). Tobacco plant extracts as environmentally benign corrosion inhibitors. Mater. Perform, 42 (2), 56-60.

[4] Noor, E. A., and Al-Moubaraki, A. H. (2008). Thermodynamic study of metal corrosion and inhibitor adsorption processes in mild steel/1-methyl-4 [4'(-X)-styryl pyridinium iodides/hydrochloric acid systems. Mater. Chem. Phy, 110 (1), 145-154.

[5] Olivares, O., Likhanova, N. V., Gomez, B., Navarrete, J., Llanos-Serrano, M. E., Arce, E., and Hallen, J. M. (2006). Electrochemical and XPS studies of decylamides of $\alpha$-amino acids adsorption on carbon steel in acidic environment. Appl. Surf. Sci, 252 (8), 2894-2909.

[6] Umoren, S. A., Ebenso, E. E., and Ogbobe, O. (2009). Synergistic effect of halide ions and polyethylene glycol on the corrosion inhibition of aluminium in alkaline medium. $J$. Appl. Polym. Sci, 113 (6), 3533-3543.

[7] Ebenso, E. E., and Oguzie, E. E. (2005). Corrosion inhibition of mild steel in acidic media by some organic dyes. Mater. Lett, 59 (17), 2163-2165.

[8] Cicek, V. and Ozdemir, M. (2013). Characterization Studies Of Aqueous Immersion Solutions Of Novel Environmentally Friendly Organometallic Corrosion Inhibitors Used To Cure Mild Steel Substrates In Corrosive Media. Int. J. Eng. Resear. Applica, 3 (1), 1455-1461.

[9] Ituen, E. B., Essien, E. A., Udo, U. E., and Oluwaseyi, O. R. (2014). Experimental and theoretical study of corrosion inhibition effect of Cucumeropsis mannii N. seed oil metallic soap of zinc on mild steel surface in sulphuric acid. Adv. Appl. Sci. Resear, 5 (3), 26-53.

[10] Essien, E. A., Umoren, S. A., Essien, E. E. and Udoh, A. P. (2012). Preparation and evaluation of Cucumeropsis mannii Naud. seed oil metallic soaps as driers in gloss paint. J. Mater. Environ. Sci, 3 (3), 477-484.

[11] Ahamed, H. A. U., Uddin, M. H., Mannan, M. A., Barua, S. and Hoque, M. A. (2014). Studies on the Isolation, PhysicoChemical Characterization and Microbial Activities of Melon (Cucumis melo) Seed Oil. Int. J. Innov. Sci. Res, 11 (1), 105111.

[12] Neogi, U., Saumya, R., Mishra, R. K. and Raju, K. C. (2008). Lipid content and in vitro antimicrobial activity of oil seeds of some Indian medicinal plants. Current Res. Bacteriol, 1, 1-6.

[13] Ekpunobi, U. E., Chukwuka, M. O., Ogbuagu, A. S., Ofora, P. U., and Ohaekenyem, E. C. (2014). Efficiency of heavy metallic soap produced from naphthalic acid recovered from used lubricating oil in paint formulation. J. Sci. Technol, 1 (5), 298-302.

[14] Owolabi, J. B., Alabi, K. A. and Lajide, L. (2015). Synthesis and characterization of copper metal soaps from Thevetia peruviana and Hura crepitans seed oils. Scientif. Res. Essays, 10 (23), 649-654.

[15] Ituen, E., Akaranta, O., and James, A. (2016). Green anticorrosive oilfield chemicals from 5-hydroxytryptophan and synergistic additives for X80 steel surface protection in acidic well treatment fluids. J. Mol. Liq, 224, 408-419. 
[16] Ebenso, E. E. (1998). Inhibition of aluminium (AA3105) Corrosion in $\mathrm{HCl}$ by acetamide and thiourea. Nig. Corros. J, 1 (1); 29-44.

[17] Ituen, E. B. and Udo, U. E. (2012). Phytochemical profile, adsorptive and inhibitive behavior of Costus afer extracts on aluminium corrosion in hydrochloric acid. Der Chem. Sin, 3 (6), 1394-1405.

[18] Lawal, A. O. and Audu, A. A. (2011). Analysis of heavy metals found in vegetables from some cultivated irrigated gardens in the Kano metropolis, Nigeria. J. Environ. Chem. Ecotoxicol, 3 (6), 142-148.

[19] El-Naggar, M. M. (2007). Corrosion inhibition of mild steel in acidic medium by some sulfa drugs compounds. Corros. Sci, 49 (5), 2226-2236.

[20] James, A. O. and Akaranta, O. (2014). Corrosion inhibition of aluminium in $2 \mathrm{M}$. sulphuric acid using acetone extract of red onion skin. Int. J. Appl. Chem. Sci. Res, 2, 1-10.

[21] Popoola, L. T., Grema, A. S., Latinwo, G. K., Gutti, B. and Balogun, A. S. (2013). Corrosion problems during oil and gas production and its mitigation. Int. J. Ind. Chem, 4 (1), 1-15.

[22] Ituen, E., Akaranta, O., James, A. (2016). Evaluation of Performance of Corrosion Inhibitors Using Adsorption Isotherm Models: An Overview. Chem. Sci. Int. J. 18 (1): 134.

[23] Ituen, E., Akaranta, O., James, A., and Sun, S. (2016). Green and sustainable local biomaterials for oilfield chemicals: Griffonia simplicifolia extract as steel corrosion inhibitor in hydrochloric acid. Sus. Mat. Technol. 11: 12-18.

[24] Solomon, M. M., Umoren, S. A., Udosoro, I. I. and Udoh, A. P. (2010). Inhibitive and adsorption behaviour of carboxymethyl cellulose on mild steel corrosion in sulphuric acid solution. Corros. Sci, 52 (4), 1317-1325.

[25] Ahamad, I. and Quraishi, M. A. (2010). Mebendazole: new and efficient corrosion inhibitor for mild steel in acid medium. Corros. Sci, 52 (2), 651-656.

[26] Ostovari, A., Hoseinieh, S. M., Peikari, M., Shadizadeh, S. R. and Hashemi, S. J. (2009). Corrosion inhibition of mild steel in $1 \mathrm{M} \mathrm{HCl}$ solution by henna extract: A. comparative study of the inhibition by henna and its constituents (Lawsone, Gallic acid, $\alpha$-d-Glucose and Tannic acid). Corros. Sci, 51 (9), 19351949.

[27] Martinez, S. and Štern, I. (2001). Inhibitory mechanism of low-carbon steel corrosion by mimosa tannin in sulphuric acid solutions. J. Appl. Electrochem, 31 (9), 973-978.

[28] Grass, G., Rensing, C. and Solioz, M. (2011). Metallic copper as an antimicrobial surface. Appl. Environ. Microbiol, 77 (5), $1541-1547$.

[29] Mathews, S., Kumar, R. and Solioz, M. (2015). Copper Reduction and Contact Killing of Bacteria by Iron Surfaces. Appl. Environ. Microbiol, 81 (18), 6399-6403. 